\title{
Pester power and its consequences: do European children's food purchasing requests relate to diet and weight outcomes?
}

Christina Y Huang ${ }^{1,2}$, Lucia A Reisch ${ }^{3}$, Wencke Gwozdz ${ }^{3}$, Dénes Molnár ${ }^{4}$, Kenn Konstabel ${ }^{5}$, Nathalie Michels ${ }^{6}$, Michalis Tornaritis ${ }^{7}$, Gabriele Eiben ${ }^{8}$, Alfonso Siani ${ }^{9}$, Juan M Fernández-Alvira ${ }^{10}$, Wolfgang Ahrens ${ }^{11,12}$, Iris Pigeot ${ }^{11,12}$ and Lauren Lissner ${ }^{8, *}$ on behalf of the IDEFICS Consortium

'Pardee Rand Graduate School, Santa Monica, CA, USA: ${ }^{2}$ RAND Corporation, Santa Monica, CA, USA:

${ }^{3}$ Department of Intercultural Communication and Management, Copenhagen Business School, Solbjerg,

Frederiksberg, Denmark: ${ }^{4}$ Department of Paediatrics, Medical Faculty, University of Pécs, Budapest, Hungary:

${ }^{5}$ National Institute for Health Development, Tallinn, Estonia: ${ }^{6}$ Department of Public Health, Ghent University,

Ghent, Belgium: ${ }^{7}$ Research and Education Institute of Child Health, Strovolos, Cyprus: ${ }^{8}$ Section for Epidemiology and Social Medicine, University of Gothenburg, PO Box 453, SE 405-30 Gothenburg, Sweden: ${ }^{9}$ Institute for Food Sciences, Unit of Epidemiology and Population Genetics, National Research Council, Avellino, Italy: ${ }^{10} \mathrm{Growth}$, Exercise, Nutrition, and Development (GENUD) Research Group, University of Zaragoza, Zaragoza, Spain:

${ }^{1}$ Leibniz Institute for Prevention Research and Epidemiology-BIPS GmbH, Bremen, Germany: ${ }^{2}$ Faculty of Mathematics and Computer Science, University of Bremen, Bremen, Germany

Submitted 9 December 2015: Final revision received 2 May 2016: Accepted 4 May 2016: First published online 14 June 2016

\begin{abstract}
Objective: Children may influence household spending through 'pester power'. The present study examined pestering through parent-child food shopping behaviours in relation to children's diet and weight status.

Design: Cross-sectional and prospective analyses drawn from the IDEFICS study, a cohort study of parents and their children. Children's height and weight were measured and their recent diets were reported by parental proxy based on the Children's Eating Habits Questionnaire-FFQ at baseline and 2-year follow-up. Parents also completed questionnaires at both time points about pestering, including whether the child goes grocery shopping with them, asks for items seen on television and is bought requested food items.

Setting: Participants were recruited from eight European countries for the IDEFICS study (non-nationally representative sample).

Subjects: Study participants were children aged 2-9 years at enrolment and their parents. A total of 13217 parent-child dyads were included at baseline. Two years later, 7820 of the children were re-examined.

Results: Most parents (63\%) at baseline reported 'sometimes' acquiescing to their children's requests to purchase specific foods. Pestering was modestly associated with weight and diet. At baseline, children whose parents 'often' complied consumed more high-sugar and high-fat foods. Children who 'often' asked for items seen on television were likely to become overweight after 2 years $(\mathrm{OR}=1 \cdot 31)$, whereas 'never' asking protected against overweight $(\mathrm{OR}=0 \cdot 72)$. Conclusions: Pestering was modestly related to diet and weight in cross-sectional, but not longitudinal analyses. Asking for items seen on television had the most robust relationships across child outcomes and over time.
\end{abstract}

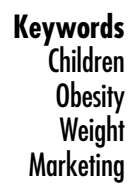

Childhood obesity is a growing global public health problem. One source of excess energy may come from children's increased purchasing power in today's consumer culture. This may take the form of children's own spending and, at younger ages, their influence over adults' spending. The latter can be achieved through persistent pestering or nagging by children. The 'ability children have to badger their parents into purchasing items they would otherwise not buy' is known as 'pester power',

As children's role in household purchases has increased, the marketing industry has responded by developing strategies directed at children. Research from a large multinational database of children aged 9-14 years showed that brand loyalty increases from the age of 10 years, creating an incentive for companies to attract 
young customers ${ }^{(2)}$. Companies may actively target children through television (TV) commercials, online marketing campaigns or front-of-package labelling - often with the use of cartoon or celebrity sponsorship. A recent review of experimental studies involving children's mascots and licensed characters found high rates of recognition for popular characters and a greater likelihood of choosing foods presented with familiar characters ${ }^{(3)}$.

Previous research from several countries has found children's products in supermarkets to be high in sugar and/or fat ${ }^{(4-6)}$. Meanwhile, TV advertisements for food during children's programming are often for unhealthy food items ${ }^{(7-9)}$. One large multi-country study documented more than 12000 TV advertisements for food on popular children's channels and found the most common advertisements were for fast foods (12\%) and candy $(12 \%)^{(7)}$. Additional mechanisms for marketing to children extend to the school environment as well as Internet and social media realms ${ }^{(10,11)}$.

Advertising to children is worrisome due to the strong body of evidence demonstrating that marketing exposure has a negative impact on diet and weight ${ }^{(1,12)}$. In fact, in 2010, the WHO released a set of recommendations to restrict marketing of foods high in saturated fat, trans-fat, added sugar or salt to children ${ }^{(13)}$. Furthermore, a recent economic analysis by the McKinsey Global Institute identified media restriction, namely restriction of highenergy food advertising, as an important approach for a multifaceted solution to obesity ${ }^{(14)}$.

Marketing may also result in increased pestering by children. A review of twelve studies examined pestering across different settings and countries, including the USA, England, India and Saudi Arabia ${ }^{(15)}$. Among these studies, eleven demonstrated an association between advertising and children's purchase requests. In surveys and interviews, mothers have frequently attributed their children's pestering for new items to advertisements, including packaging, characters and commercials ${ }^{(16,17)}$.

In one of the earliest studies to identify pester power, an observational field study of children aged 3-11 years during a grocery store trip, the children made an average of fifteen purchase requests - mostly for cereal and candy - and almost half ( $45 \%$ ) of all requests were successful ${ }^{(18)}$. More recently, an observational study of parent-child supermarket shoppers found parents purchased approximately half (52\%) of the products children verbally requested ${ }^{(19)}$. Others have estimated that nagging is responsible for $34 \%$ of children's food sales ${ }^{(20)}$. Children often pester for unhealthy foods. For example, in a study of British parents, researchers found correlations between children's attempts to influence their parent's purchases and the type of product, with the strongest correlations for sweets, snack foods and cereals ${ }^{(21)}$.

Given children's preference for both high-sugar and high-fat foods ${ }^{(22,23)}$, and the powerful forces of marketing such items to children, it is plausible that frequent compliance with children's food requests could result in unhealthy diets. However, the effect of pestering on health outcomes is unknown. We are not aware of any study that prospectively examines 'pestering' in relation to diet and changes in weight status, from an international perspective. Looking at eight European countries for evidence, the present study identified predictors of diet and weight status by examining pestering in the parentchild shopping relationship, including shopping together, item requests and request compliance.

\section{Methodology}

\section{Study sample}

The IDEFICS (Identification and prevention of dietary- and lifestyle-induced health effects in children and infants) study is a longitudinal study of 16228 children aged 2-9 years from selected survey centres in eight European countries participating in the baseline survey: Hungary, Italy, Cyprus, Estonia, Belgium, Germany, Spain and Sweden. A detailed description of the study design and sample characteristics has been published previously ${ }^{(24)}$. In brief, participants in the IDEFICS study were recruited through school settings to receive a multidimensional obesity prevention intervention consisting of changes at the community, school and home settings. All participating centres obtained approval from their governing ethical committees; all children gave oral assent after parents had provided written informed consent. It should be noted that the country-specific cohorts were not sampled to yield nationally representative estimates of anthropometric or behavioural characteristics. The baseline survey was conducted between September 2007 and May 2008 with follow-up 2 years later. At each survey, weights and heights of children were measured and a parent questionnaire was completed. As part of the questionnaires, parents reported on their children's behaviours, including an FFQ and questions about other food-related behaviours, including family food purchasing patterns and children's purchase requests. We limited our crosssectional analyses to 13217 parent-child dyads with complete baseline information on the variables of interest. Additional prospective analyses were conducted on a subset of 7820 dyads with complete 2-year follow-up information. Between the baseline and follow-up surveys, a health promotion intervention was implemented in all participating countries, with control and intervention communities that were matched on area-level sociodemographic characteristics. A more detailed description of the intervention is published elsewhere ${ }^{(25)}$. In short, the intervention included six programme objectives: (i) increasing water consumption; (ii) increasing fruit and vegetable consumption; (iii) decreasing daily TV viewing time; (iv) increasing daily physical activity levels; (v) strengthening parent-child relationships by spending 
more time together; and (vi) establishing adequate sleep duration patterns. Overall, there was no difference in weight or diet outcomes as a result of the intervention, as previously reported elsewhere ${ }^{(26,27)}$.

\section{Definition of pester power}

We examined three different but related aspects of pestering with questions driven and developed by previous consumer research; namely, research that identifies parents as key gatekeepers, communication buffers and responsible agents for helping their children to learn how to navigate within a commercial environment and control one's spontaneous desires ${ }^{(28-30)}$.

First, parents were asked 'Do you usually take your child along grocery shopping?' and selected from four answer choices, including 'I try to avoid it because it is faster alone', 'I try to avoid it because he/she is pushing for treats', 'I enjoy choosing the food together with my child' and 'I have to, but don't enjoy it'. This question assesses exposure to shopping situations and avoidance behaviour of parents. The rationale is that the more often children are taken along grocery shopping, the more opportunities for teaching consumer and food literacy, the more opportunities for the child to exert pester power and the more exposed the child is to shopping stimulation. Grocery shopping is part of a regular routine and parent's handling of such situations is based on previous experience. One reason to avoid taking children is that it takes longer ('I try to avoid it because it is faster alone'), another reason is to avoid pestering and to prevent arguing in an often stressful situation in a public space (' $I$ try to avoid it because he/she is pushing for treats'). On the other hand, parents might regard shopping with their children as joyful common time or even a teachable moment ('I enjoy choosing the food together with my child'); whereas others might simply have no alternative ('I have to, but don't enjoy it').

Second, parents were asked to report categorical frequencies for TV-stimulated specific pestering in response to 'Does your child ask for items he/she saw on TV?' Options included 'never', 'sometimes', 'often' and 'my child hardly watches TV'.

Finally, parents self-reported 'When your child asks for a specific food item which is not on your shopping list, do you buy it?' as a measure of giving in to their children's product requests. Response options included 'usually not', 'sometimes', 'often', 'only if there is extra money' and 'only when the item is healthy'.

\section{Weight and diet outcomes}

The primary outcome reported here was weight status at baseline and change over 2 years. Study staff recorded child height and weight during a physical examination at each time point. Standing height was measured using a Seca 225 stadiometer (Seca, Birmingham, UK) and body weight was measured using a prototype of the TANITA BC 420 SMA digital scale (TANITA Europe GmbH, Sindelfingen, Germany). BMI was calculated as $\mathrm{kg} / \mathrm{m}^{2}$. BMI $Z$-scores were calculated using procedures developed by the US Centers for Disease Control and Prevention. BMI $Z$-scores greater than or less than 3 were excluded from analyses to remove extreme and illogical values. Obese weight status was defined as BMI in the 95th percentile or above for age and sex based upon the Centers for Disease Control and Prevention growth charts. Overweight status was defined as BMI in the 85th percentile or above. The Centers for Disease Control and Prevention definition of weight status differs from other reference systems, resulting in different prevalences of overweight and obesity. A comparison of the prevalences observed using different classifications systems in the IDEFICS cohort is published elsewhere ${ }^{(31)}$.

The secondary outcomes were propensity to consume foods high in sugar and foods high in fat based on the food frequency section of the Children's Eating Habits Questionnaire (CEHQ-FFQ). This instrument was designed to be completed by parental proxy, to reflect children's consumption of foods while at home or with parents, over the past 4 weeks. The CEHQ-FFQ has been found to be reproducible with mean $\kappa$ coefficients ranging from 0.41 to 0.60 and Spearman's correlation higher than 0.5 for $81 \%$ of the food items ${ }^{(32)}$, and a validation study of the CEHQ-FFQ against repeated $24 \mathrm{~h}$ dietary recalls found that under $12 \%$ of the food groups were misclassified ${ }^{(33)}$. Because the questionnaire includes various foods and drinks that are high in added sugars and fats, indicators have been developed to reflect recent consumption of these items, relative to all items. Parents recorded typical consumption frequency of forty-three pan-European food items from fourteen food groups during the preceding 4 weeks for their child's meals at home and when under parental control. Frequency categories were 'never/less than once a week', ' $1-3$ times a week', ' $4-6$ times a week', '1 time per day', '2 times per day', '3 times per day', ' 4 or more times per day' and 'I have no idea'. Sugar propensity was calculated as the percentage of high-sugar foods out of all foods consumed at home in one week. High-sugar foods included fresh fruit with added sugar, fruit juice, sugar-sweetened drinks, diet soft drinks, sweetened breakfast cereals, sweetened milk, sweetened yoghurt, jam/honey, chocolate- or nut-based spread, chocolate-based candies, non-fat candies, cake/pudding/ cookies and ice cream. Similarly, fat propensity was calculated as the percentage of high-fat foods out of all foods consumed at home in one week. High-fat foods included fried potatoes, whole-fat milk, whole-fat yoghurt, fried fish, cold cuts/sausages, fried meat, fried eggs, mayonnaise, cheese, chocolate- or nut-based spread, butter/margarine on bread, nuts/seeds/dried fruits, salty snacks, savoury pastries, chocolate-based candies, cake/ pudding/cookies and ice cream. The sugar and fat 
propensities have previously been used to describe eating habits in children ${ }^{(32,34)}$ and correlate with the percentage intakes of sugar and fat reported by a $24 \mathrm{~h}$ dietary recall ${ }^{(34)}$.

\section{Statistical analyses}

Chi-square tests were used to explore country differences in the pester power variables. Regression analyses were used to estimate relationships between the pester variables and outcomes of interest in cross-sectional and prospective analyses. Each of the three pester variables was entered into separate analyses. All regression analyses were adjusted for age, sex, country and maximum parent education. Categorical dummy variables were used for sex, country and maximum parent education (International Standard Classification of Education (ISCED) levels $0-6)^{(35)}$. For the prospective analyses, additional adjustments were made. Prevalent cases at baseline were excluded from analyses with dichotomous 2-year outcomes (overweight, obese). We report odds ratios with $95 \%$ confidence intervals for these dichotomous outcomes. In regression models with continuous outcomes (BMI $Z$-score, sugar propensity, fat propensity), we controlled for baseline levels and report effect estimates $b$ and the corresponding standard errors in tables. All prospective analyses controlled for whether or not the parent-child dyad received the multidimensional intervention; however, there were no differences in weight or diet outcomes between the two groups. All statistical tests were conducted without adjusting for multiplicity using the statistical software package Stata version 11 . Accordingly, all statistical results should be interpreted from a more exploratory view. For the sake of convenience, effects that are statistically significant at a $0.1 \%$, $1 \%$ or $5 \%$ level are indicated in the respective tables.

Additional stratified and multilevel models were used to conduct sensitivity analyses, focusing on the question about the child asking for items on TV. We used a randomeffects multilevel model (individuals nested within countries). We also examined potential interactions of country and age with asking for items on TV. Finally, we tested for differences between boys and girls.

\section{Results}

\section{Sample characteristics}

A total of 13217 children with complete data were included in the baseline analytic sample. Descriptive statistics are shown in Table 1. The sample was evenly split between boys and girls. Half of the children had parents with a maximum ISCED of 3 or 4 , equivalent to upper secondary or post-secondary non-tertiary education. The mean age of the children was 6.0 years. Only one-tenth (11\%) of the children were obese at baseline; however, one-quarter (24\%) were overweight.
Table 1 Sample characteristics; IDEFICS (Identification and prevention of dietary- and lifestyle-induced health effects in children and infants) study - baseline (September 2007-May 2008)

\begin{tabular}{|c|c|c|}
\hline & $n$ & $\%$ \\
\hline Total & 13217 & \\
\hline \multicolumn{3}{|l|}{ Country } \\
\hline Italy & 2088 & $15 \cdot 8$ \\
\hline Estonia & 1618 & $12 \cdot 2$ \\
\hline Cyprus & 942 & $7 \cdot 1$ \\
\hline Belgium & 1482 & 11.2 \\
\hline Sweden & 1613 & $12 \cdot 2$ \\
\hline Germany & 1720 & 13.0 \\
\hline Hungary & 2390 & $18 \cdot 1$ \\
\hline Spain & 1364 & $10 \cdot 3$ \\
\hline Female & 6526 & 49.4 \\
\hline \multicolumn{3}{|l|}{ Parent ISCED } \\
\hline Pre-primary & 89 & 0.7 \\
\hline Primary & 243 & 1.8 \\
\hline Lower secondary & 1061 & 8.0 \\
\hline Upper secondary & 4643 & $35 \cdot 1$ \\
\hline Post-secondary & 2192 & $16 \cdot 6$ \\
\hline First-stage tertiary & 4129 & 31.2 \\
\hline Second-stage tertiary & 860 & 6.5 \\
\hline Obese & 1472 & $11 \cdot 1$ \\
\hline \multirow[t]{2}{*}{ Overweight } & 3112 & 23.5 \\
\hline & Mean & SD \\
\hline Age (years) & 6.01 & 1.81 \\
\hline BMI Z-score & 0.22 & 1.11 \\
\hline Sugar propensity & 25.5 & 11.74 \\
\hline Fat propensity & $25 \cdot 8$ & 9.41 \\
\hline
\end{tabular}

ISCED, International Standard Classification of Education.

\section{Pester prevalence}

Table 2 describes the patterns of pester behaviours by country. Approximately half of the parents (55\%) reported that they took their child grocery shopping (either 'I enjoy choosing the food together with my child' or 'I have to, but don't enjoy it'). Reasons for avoiding shopping together varied by country (Pearson $\chi_{21}^{2}=851.28 ; \quad P<0.001$ ). Parents from Sweden and Germany had the lowest proportion ( 2 and $3 \%$, respectively) reporting 'I try to avoid it because he/she is pushing for treats', compared with one in five parents from Cyprus (21\%).

Country differences also existed in TV-motivated pestering (see Table 2; Pearson $\chi_{21}^{2}=2421.85 ; P<0 \cdot 001$ ). Only $3 \%$ of Swedish children 'often' asked for items seen on TV, but up to one-quarter of Italian (26\%) and Hungarian (23\%) children 'often' asked for such items. The most common response among all countries was that children 'sometimes' asked for items from TV.

When parents were asked about how often they bought specific food items the child asked for that were not on their shopping lists, most parents (range 51-69\%) reported 'sometimes' purchasing requested items (see Table 2; Pearson $\left.\chi_{28}^{2}=1830 \cdot 19 ; \quad P<0 \cdot 001\right)$. One-third (32\%) of Spanish parents and one-quarter (25\%) of Swedish parents reported 'usually not' fulfilling such requests. A small fraction (11\%) of parents reported buying the requested item 'only if it is something healthy'. 
Table 2 Characteristics of child-parent behaviours regarding shopping by country; IDEFICS (Identification and prevention of dietary- and lifestyle-induced health effects in children and infants) study - baseline (September 2007-May 2008)

\begin{tabular}{|c|c|c|c|c|c|c|c|c|c|}
\hline & \multicolumn{8}{|c|}{ Country } & \multirow[b]{2}{*}{$\begin{array}{l}\text { All countries } \\
(n 13217)\end{array}$} \\
\hline & $\begin{array}{c}\text { Italy } \\
(n 2088)\end{array}$ & $\begin{array}{l}\text { Estonia } \\
(n \text { 1618) }\end{array}$ & $\begin{array}{l}\text { Cyprus } \\
(n \text { 942) }\end{array}$ & $\begin{array}{l}\text { Belgium } \\
(n \text { 1482) }\end{array}$ & $\begin{array}{l}\text { Sweden } \\
(n \text { 1613) }\end{array}$ & $\begin{array}{l}\text { Germany } \\
(n 1720)\end{array}$ & $\begin{array}{l}\text { Hungary } \\
(n \text { 2390) }\end{array}$ & $\begin{array}{l}\text { Spain } \\
(n \text { 1364) }\end{array}$ & \\
\hline \multicolumn{10}{|c|}{ Do you usually take your child along to grocery shopping? (\%) } \\
\hline $\begin{array}{l}\text { I try to avoid it because it is } \\
\text { faster alone }\end{array}$ & 29 & 36 & 35 & 38 & 44 & 34 & 37 & 41 & 36 \\
\hline $\begin{array}{l}\text { I try to avoid it because he/she } \\
\text { is pushing for treats }\end{array}$ & 18 & 13 & 21 & 5 & 2 & 3 & 6 & 10 & 9 \\
\hline $\begin{array}{l}\text { I enjoy choosing the food } \\
\text { together with my child }\end{array}$ & 49 & 44 & 37 & 55 & 48 & 57 & 52 & 39 & 49 \\
\hline I have to, but don't enjoy it & 5 & 7 & 8 & 2 & 6 & 5 & 5 & 10 & 6 \\
\hline \multicolumn{10}{|c|}{ Does your child ask for items he/she saw on TV? $(\%)^{\star \star \star}$} \\
\hline Never & 6 & 12 & 5 & 27 & 47 & 15 & 6 & 35 & 18 \\
\hline Sometimes & 67 & 72 & 65 & 65 & 48 & 67 & 67 & 51 & 63 \\
\hline Often & 26 & 14 & 29 & 6 & 3 & 12 & 23 & 8 & 15 \\
\hline My child hardly watches TV & 2 & 2 & 2 & 3 & 2 & 6 & 3 & 6 & 3 \\
\hline \multicolumn{10}{|c|}{ When your child asks for a specific food item which is not on your shopping list, do you buy it? $(\%)^{\star \star \star}$} \\
\hline Usually not & 6 & 10 & 6 & 13 & 25 & 14 & 4 & 32 & 13 \\
\hline Sometimes & 61 & 66 & 51 & 69 & 59 & 68 & 54 & 51 & 60 \\
\hline Often & 19 & 10 & 16 & 10 & 3 & 7 & 20 & 5 & 12 \\
\hline $\begin{array}{l}\text { Only if I have the money for } \\
\text { extras }\end{array}$ & 1 & 4 & 5 & 1 & 2 & 5 & 9 & 0 & 4 \\
\hline Only if it is something healthy & 12 & 11 & 22 & 6 & 11 & 7 & 14 & 11 & 11 \\
\hline
\end{tabular}

TV, television.

${ }^{\star \star \star} P<0.001$.

\section{Cross-sectional analyses}

The cross-sectional analyses showed a number of relationships between baseline shopping behaviours and weight and diet outcomes (see Table 3). Parents who avoided shopping with their children because they push for treats were more likely to have children who were obese $(\mathrm{OR}=1.25 ; 95 \%$ CI $1.05,1.49)$ or overweight (OR $=1.18 ; 95 \%$ CI $1.03,1.36)$ compared with parents who reported that they enjoyed choosing foods with their child. Children who pushed for treats also had higher BMI $Z$-scores, sugar propensity and fat propensity.

Parents whose children 'often' asked for items seen on TV were more likely to have obese (OR $=1 \cdot 19 ; 95 \%$ CI $1.03,1.37)$ or overweight (OR $=1.22 ; 95 \%$ CI $1.09,1.36)$ children. 'Often' asking for items was also associated with higher BMI $Z$-scores and sugar and fat propensities. Children who 'never' asked for items from TV or 'hardly watch TV' had lower propensities to consume sugar, but not fat. Children who 'hardly watch TV' had a significantly lower proportion of high-sugar foods in their diet.

Whether the parents purchased requested items was not associated with weight status, but was significantly correlated with sugar and fat. Children whose parents usually did not purchase requests had lower sugar $(b=-2 \cdot 28, \quad \mathrm{SE}=0 \cdot 29)$ and fat propensities $(b=-1.57$, $\mathrm{SE}=0 \cdot 25)$. Similarly, children whose parents only bought requested items that were healthy had lower sugar and fat propensities, although the differences were not as large. Children whose parents 'often' bought requested items had diets with almost $4 \%$ higher frequency of sugary foods and $2 \%$ higher frequency of high-fat foods, relative to total number of foods consumed. Interestingly, parents who reported buying requested items only if there was money for extras had children whose diets were higher in sugar and fat.

\section{Prospective analyses}

A total of 7820 children had complete information at the 2-year follow-up. A few associations persisted over time (see Table 4). Whether the parent had usually taken the child grocery shopping did not appear to be associated with weight after 2 years. There were significant relationships between the 'I try to avoid it because it is faster alone' group and diet, but these translated to less than half a percentage point each in lower frequency of high-sugar foods and high-fat foods. Pushing for treats at baseline was not associated with worse weight or dietary outcomes at the 2-year follow-up.

Asking for items on the TV remained associated with increased odds of becoming overweight. Those who 'never' asked for such items were less likely to become overweight (OR $=0.72 ; 95 \%$ CI $0.55,0.96)$ while those who 'often' asked were more likely to become overweight $(\mathrm{OR}=1.31 ; 95 \%$ CI $1.02,1.68)$. Obesity at the 2-year follow-up was not related to asking for items at baseline. A few differences in BMI $Z$-scores and diet outcomes were of marginal magnitude, but statistically significant.

Whether the parent purchased items their child asked for remained unassociated with prospective weight outcomes. 'Usually not' purchasing items was significantly associated with lower sugar and fat propensities in the 
Table 3 Cross-sectional associations between parent-child consumer behaviours and child weight/diet outcomes; IDEFICS (Identification and prevention of dietary- and lifestyle-induced health effects in children and infants) study - baseline (September 2007-May 2008)

\begin{tabular}{|c|c|c|c|c|c|c|c|c|c|c|}
\hline & \multicolumn{10}{|c|}{ Outcome } \\
\hline & \multicolumn{2}{|c|}{ Obese (BMI $\geq 95$ th percentile) } & \multicolumn{2}{|c|}{ Overweight (BMI $\geq 85$ th percentile) } & \multicolumn{2}{|c|}{ BMI Z-score } & \multicolumn{2}{|c|}{ Sugar propensity } & \multicolumn{2}{|c|}{ Fat propensity } \\
\hline & OR & $95 \% \mathrm{Cl}$ & OR & $95 \% \mathrm{Cl}$ & $b$ & SE & $b$ & SE & $b$ & SE \\
\hline \multicolumn{11}{|l|}{ Do you usually take your child along to grocery shopping? } \\
\hline I try to avoid it because it is faster alone & $0.87^{*}$ & $0.76,0.99$ & 0.93 & $0.85,1.02$ & -0.01 & 0.02 & $0.42^{*}$ & 0.2 & $0.55^{\star \star}$ & 0.17 \\
\hline I try to avoid it because he/she is pushing for treats & $1.25^{*}$ & $1.05,1.49$ & $1 \cdot 18^{*}$ & $1.03,1.36$ & $0 \cdot 10^{\star *}$ & 0.03 & $1.70^{\star \star \star}$ & 0.34 & $1.44^{\star \star \star}$ & 0.29 \\
\hline I enjoy choosing the food together with my child & \multicolumn{2}{|c|}{ Ref. } & \multicolumn{2}{|r|}{ Ref. $1.00,1.00$} & \multicolumn{2}{|c|}{ Ref. } & \multicolumn{2}{|c|}{ Ref. } & \multicolumn{2}{|c|}{ Ref. } \\
\hline I have to, but don't enjoy it & 0.82 & $0.63,1.07$ & 0.95 & $0.79,1.14$ & -0.01 & 0.04 & $1.71^{\star \star \star}$ & 0.4 & $1.53^{\star \star \star}$ & 0.35 \\
\hline \multicolumn{11}{|l|}{ Does your child ask for items he/she saw on TV? } \\
\hline $\begin{array}{l}\text { Never } \\
\text { Sometimes }\end{array}$ & \multicolumn{2}{|c|}{ Ref. } & \multicolumn{2}{|r|}{ Ref. } & \multicolumn{2}{|c|}{$\begin{array}{c}-0.06^{*} \\
\text { Ref. }\end{array}$} & \multicolumn{2}{|c|}{ Ref. } & \multicolumn{2}{|c|}{${ }_{\text {Ref. }}^{-0.26}{ }^{0.23}$} \\
\hline Often & $1.19^{*}$ & $1.03,1.37$ & $1 \cdot 22^{\star \star \star}$ & $1.09,1.36$ & $0.10^{\star \star *}$ & 0.03 & $1.72^{\star \star \star}$ & 0.26 & $1.74^{\star \star *}$ & 0.23 \\
\hline My child hardly watches TV & 0.80 & $0.54,1.19$ & 0.86 & $0.66,1 \cdot 11$ & $-0.12^{\star}$ & 0.05 & $-3 \cdot 60^{\star \star \star}$ & 0.53 & -0.79 & 0.46 \\
\hline \multicolumn{11}{|c|}{ When your child asks for a specific food item which is not on your shopping list, do you buy it? } \\
\hline Usually not & 1.01 & $0.83,1.22$ & \multirow{2}{*}{\multicolumn{2}{|c|}{ Ref. $0.92,1.21$}} & \multirow{2}{*}{\multicolumn{2}{|c|}{0.04 Ref. ${ }^{0.03}$}} & $-2 \cdot 28^{\star \star *}$ & 0.29 & $-1.57^{\star \star \star}$ & 0.25 \\
\hline Sometimes & \multicolumn{2}{|c|}{ Ref. } & & & & & Ref & & \multicolumn{2}{|c|}{ Ref. } \\
\hline Often & 1.05 & $0.89,1.24$ & 1.04 & $0.92,1 \cdot 19$ & 0.03 & 0.03 & $3.73^{\star \star \star}$ & 0.29 & $2 \cdot 00^{\star \star \star}$ & 0.26 \\
\hline Only if there is extra money & 1.20 & $0.90,1.60$ & 1.09 & $0.87,1.36$ & 0.06 & 0.05 & $1.64^{\star \star \star}$ & 0.5 & $1.07^{\star}$ & 0.43 \\
\hline Only if the item is healthy & 0.90 & $0.75,1.09$ & 0.92 & $0.80,1.05$ & -0.03 & 0.03 & $-1 \cdot 81^{\star \star \star}$ & 0.3 & $-0.56^{\star}$ & 0.26 \\
\hline Observations $(n)$ & \multicolumn{2}{|c|}{13217} & \multicolumn{2}{|r|}{13217} & \multicolumn{2}{|c|}{13217} & \multicolumn{2}{|c|}{13217} & \multicolumn{2}{|c|}{13217} \\
\hline
\end{tabular}

TV, television; Ref., reference category.

Independent logistic (obese, overweight) and linear (BMI, sugar propensity, fat propensity) regression analyses. All analyses controlled for child's age, sex, country and parent's education.

${ }^{\star} P<0.05,{ }^{* *} P<0.01,{ }^{* * *} P<0.001$. 


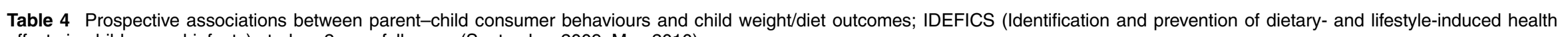
effects in children and infants) study - 2-year follow-up (September 2009-May 2010)

\begin{tabular}{|c|c|c|c|c|c|c|c|c|c|c|}
\hline & \multicolumn{10}{|c|}{ Outcome } \\
\hline & \multicolumn{2}{|c|}{ Obese (BMI $\geq 95$ th percentile) } & \multicolumn{2}{|c|}{ Overweight (BMI $\geq 85$ th percentile) } & \multicolumn{2}{|c|}{ BMI Z-score } & \multicolumn{2}{|c|}{ Sugar propensity } & \multicolumn{2}{|c|}{ Fat propensity } \\
\hline & OR & $95 \% \mathrm{Cl}$ & OR & $95 \% \mathrm{Cl}$ & $b$ & SE & $b$ & SE & $b$ & SE \\
\hline \multicolumn{11}{|l|}{ Do you usually take your child along to grocery shopping? } \\
\hline try to avoid it because it is faster alone & 0.86 & $0.64,1.16$ & 0.92 & $0.75,1.13$ & 0.00 & 0.01 & $0.46^{*}$ & 0.22 & $0.47^{*}$ & 0.21 \\
\hline I try to avoid it because he/she is pushing for treats & \multirow{2}{*}{\multicolumn{2}{|c|}{ Ref. $0.15,1.61$}} & \multirow{2}{*}{\multicolumn{2}{|c|}{ Ref. $0.81,1.49$}} & \multirow{2}{*}{\multicolumn{2}{|c|}{${ }^{-0.01}{ }_{\text {Ref. }} 0.02$}} & 0.58 & 0.36 & 0.60 & 0.34 \\
\hline I enjoy choosing the food together with my child & & & & & & & \multicolumn{2}{|c|}{ Ref. 0.30} & \multicolumn{2}{|c|}{ Ref. } \\
\hline I have to, but don't enjoy it & 0.72 & $0.39,1.34$ & 0.95 & $0.64,1.41$ & 0.02 & 0.03 & 0.35 & 0.43 & -0.08 & 0.4 \\
\hline \multicolumn{11}{|l|}{ Does your child ask for items he/she saw on TV? } \\
\hline Never & 0.63 & $0.40,1.01$ & $0.72^{*}$ & $0.55,0.96$ & $-0.07^{\star \star \star}$ & 0.02 & -0.53 & 0.28 & 0.10 & 0.26 \\
\hline Sometimes & \multicolumn{2}{|c|}{ Ref. } & \multicolumn{2}{|r|}{ Ref. } & \multicolumn{2}{|c|}{ Bef } & \multicolumn{2}{|c|}{ Ref. } & \multicolumn{2}{|c|}{ Ref. } \\
\hline Often & 1.15 & $0.84,1.59$ & $1.31^{*}$ & $1.02,1.68$ & 0.02 & 0.02 & 0.45 & 0.3 & $0.68^{*}$ & 0.28 \\
\hline My child hardly watches TV & 0.38 & $0.12,1.21$ & 0.63 & $0.33,1.18$ & $-0.11^{\star \star}$ & 0.04 & -0.54 & 0.59 & 0.61 & 0.55 \\
\hline \multicolumn{11}{|c|}{ When your child asks for a specific food item which is not on your shopping list, do you buy it? } \\
\hline $\begin{array}{l}\text { Usually not } \\
\text { Sometimes }\end{array}$ & \multicolumn{2}{|c|}{ Ref. $0.59,1.43$} & \multicolumn{2}{|r|}{ Ref. $0.79,1.38$} & \multicolumn{2}{|c|}{${ }^{-0.02}{ }_{\text {Ref. }} 0.02$} & Ref. & 0.3 & $\begin{array}{r}-1.03^{* \star *} \\
\operatorname{Re}\end{array}$ & 0.28 \\
\hline Often & $1 \cdot 13$ & $0.78,1.64$ & 1.02 & $0.76,1.37$ & 0.02 & 0.02 & $1.93^{\star * *}$ & 0.34 & 0.32 & 0.32 \\
\hline Only if there is extra money & 1.09 & $0.49,2.41$ & 1.00 & $0.55,1.80$ & -0.04 & 0.04 & -0.39 & 0.64 & 1.17 & 0.6 \\
\hline Only if the item is healthy & 0.78 & $0.50,1.21$ & 0.97 & $0.72,1.31$ & -0.02 & 0.02 & -0.08 & 0.33 & $-1 \cdot 20^{\star \star \star}$ & 0.3 \\
\hline Observations $(n)$ & \multicolumn{2}{|c|}{6975} & \multicolumn{2}{|r|}{6026} & \multicolumn{2}{|c|}{7820} & \multicolumn{2}{|c|}{7820} & \multicolumn{2}{|c|}{7820} \\
\hline
\end{tabular}

TV, television; Ref., reference category.

Independent logistic (obese, overweight) and linear (BMI, sugar propensity, fat propensity) regression analyses. All analyses controlled for age, sex, country, parent's education and intervention group. Obese (overweight) analyses limited to children who were not obese (overweight) at baseline. BMI, sugar propensity and fat propensity analyses controlled for their respective baseline levels.

${ }^{\star} P<0.05,{ }^{\star *} P<0.01,{ }^{* \star *} P<0.001$. 


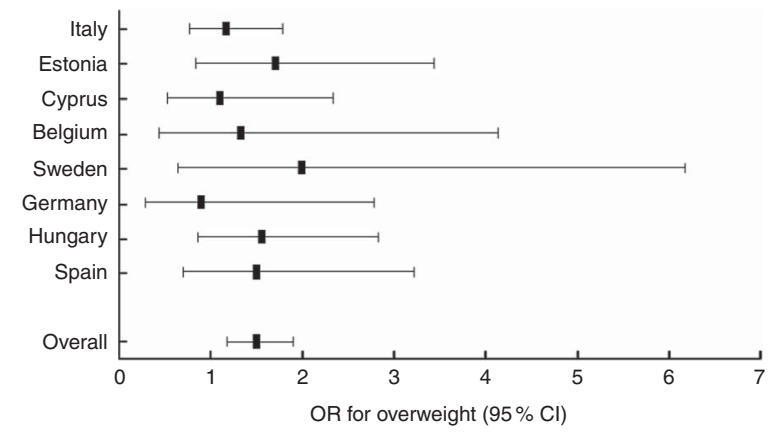

Fig. 1 Association between often asking for items seen on television and child overweight status at 2-year follow-up by country; IDEFICS (Identification and prevention of dietary- and lifestyle-induced health effects in children and infants) study (September 2009-May 2010). Odds ratios for overweight (BMI $\geq 85$ th percentile) with their $95 \%$ confidence intervals represented by horizontal bars

child's diet, although these differences appear to be smaller than corresponding differences in the cross-sectional analysis. Having 'often' purchased items was associated with a higher sugar propensity, but not fat propensity. In contrast, buying 'only if the item is healthy' was associated with a lower fat propensity, but not sugar propensity.

\section{Sensitivity analyses}

We conducted sensitivity analyses to ensure the robustness of our results, focusing on the question about how often the child asks for items on TV as this appeared to be the pester variable with the largest association with weight status and diet. The random-effects multilevel model yielded similar results to our original model with country-fixed effects: all cross-sectional and prospective associations were in the same direction and of similar magnitude. We examined whether the prospective analysis of overweight was due to a country effect and found no evidence of interaction between country and asking for items on TV. In individual country analyses, differences in weight outcomes for children who 'often' asked for items from TV could not be detected, although they were significant in the pooled sample (see Fig. 1). We tested for interaction with age and found that the effect on the weight outcomes was stronger in the older children. When we tested for differences between boys and girls, we found no significant sex differences, even for the diet outcomes of sugar and fat propensity scores. The associations with asking for items from TV remained strong and significant in cross-sectional analyses for both the boys and girls in sex-stratified analyses.

\section{Discussion}

Pestering was modestly related to diet and weight in this multi-country sample and we found more cross-sectional, rather than prospective, associations. Children who were perceived as pushing for treats, who often asked for items on TV and whose parents often gave in to purchase requests had diets that were higher in both fat and sugar. Over the 2-year follow-up time, children who never asked for items seen on TV were less likely to become overweight, while children who often asked were more likely. Pestering also displayed major variations in its prevalence across the eight countries. These differences in pestering behaviour may be attributed to culture or governmental intervention. For example, Sweden, which has strict regulations on commercials for children's TV programmes ${ }^{(36)}$ that effectively limit exposure to marketing, had the lowest proportion of children who often ask for items from TV.

It is interesting to note that pushing for treats at baseline, which was associated with worse diets and weight outcomes in the cross-sectional analyses, did not have the same negative outcomes in the longitudinal analyses. This may suggest that preventing exposure over time to the stimulation that comes from grocery shopping may nullify the increased health risks associated with pestering. However, given the lack of longitudinal associations with the different shopping behaviours, it may be that parental behaviour measured 2 years ago is not a very strong predictor of weight and diet.

Previous research has found that children prefer and request high-fat and high-sugar items ${ }^{(18)}$; thus it is not surprising that in our study, children whose requests were granted consumed diets associated with higher sugar and fat. A small proportion of parents ( $4 \%$ ) reported giving in to their child's requests if there was extra money. These children's diets were associated with higher sugar and fat, but less than in the group of children whose requests were often granted. This suggests that financial constraints may limit poor dietary habits brought on through pestering. In addition, children whose parents bought requested items deemed 'healthy' consumed a lower proportion of foods with sugar and fat than the reference group (children whose parents 'sometimes' bought requested items); however, the difference in fat was smaller than in those children whose parents routinely refused. Since the diet scores are proportional measures, the 'healthy' items appear to still be contributing fat. Such results might indicate that highly restrictive parents are more effective at managing their child's pestering and overall diet, or that parents' perceptions of 'healthy' need to be redefined.

An online survey of UK parents found that as many as $40 \%$ of parents felt they did not have enough information about children's healthy diets and that parental knowledge about appropriate nutritional guidelines was worse for older children, so that as they grow older and adopt more sophisticated pestering strategies, parents are less equipped with diet knowledge ${ }^{(16)}$. The same study also found that $80 \%$ of mothers had been asked by their children to buy an advertised food product, which is similar to our finding that $78 \%$ of children sometimes or often asked for items from TV. 
The present study is subject to several limitations. Parents might be reluctant to answer honestly about how often they give in to their child's requests. To address such a social desirability bias, parents were assured of the confidentiality of all their responses, but this is unlikely to fully eliminate this type of biased reporting. However, if parents were reluctant to admit buying items their children asked for, this bias would under-report pester power and the true differences could be larger than those observed herein. In addition, one of the questions about pestering ('Does your child ask for items he/she saw on TV?') asks about the child's behaviour, rather than the parent's behaviour, which may reduce the aforesaid bias associated with self-report. Although this question does not explicitly ask about food items, given that the preceding question is about grocery shopping and the succeeding question is about the child asking for specific food items, we expect that parents were thinking about their child's behaviours related to food.

Other limitations of the study include the discrepancies between cross-sectional and prospective results. Longerterm health outcomes were not present at follow-up where they would have been most expected if the relationship was causal. These discrepancies may be due to the considerably decreased sample size from baseline to follow-up with resulting loss of statistical power. Alternatively, the relatively short time of 2 years may have been insufficient to detect associations of the same magnitude seen at baseline which might reflect more years of exposure or changes in other lifestyle factors, such as activity level, that we did not account for. Still, the stronger cross-sectional results cannot be considered causal and may in some instances reflect reverse causation. For instance, children whose parents avoided shopping with them because the child pushed for treats were heavier and had worse diets, but it could be the case that avoiding shopping is driven by the child's weight status, rather than the other way around.

We did not include parental BMI or diet in our analyses. Although these measures can be strongly correlated with child outcomes - both through genetic and environmental influences - we did not collect information on parental diet, and self-reported height and weight were not available for all parents.

Finally it must be acknowledged that the dietary instrument has certain weaknesses including the fact that it is too short to capture the whole diet and is limited to foods that the parent is in control of. Although it has been validated against a $24 \mathrm{~h}$ recall with moderately favourable results ${ }^{(33)}$, the strength of this outcome is far lower than those based on measured anthropometry.

However, the study is not without strengths including the fact that the design was standardized across eight European countries with varying obesity prevalence, food cultures and legislation regarding advertising to children. All anthropometric measures and parental questionnaires were designed to capture the same information across all eight survey countries representing northern, southern, eastern and western parts of Europe. Thus it is one of the few studies that can examine associations between pestering behaviours and health outcomes in a large, aggregated data set, while also considering the profound differences in context that exist between countries.

Advertising exposure is one avenue for change with the potential to span across these cultural divides. In our study, asking for items from TV had a robust relationship with diet and weight. Previously, researchers across eleven countries coded TV advertisements on popular children's TV channels and found on average that $18 \%$ of advertisements were for food; of those, $67 \%$ were for non-core foods such as fast foods, snack foods and candy ${ }^{(7)}$. Based on those findings, the authors estimated that a child who watches $2 \mathrm{~h}$ of TV programming daily would be exposed to approximately fifty-six to 126 food advertisements per week. Both Galst and White ${ }^{(18)}$ and Chamberlain et al. ${ }^{(37)}$ found positive correlations between children's media exposure and the number of requests they made. Although children in another study reported being influenced by advertisements for foods high in fat, sugar and salt, their actual consumption was related to parental control $^{(28)}$. This finding has implications for interventions at the parental level and supports a recommendation that parents are important actors in educating children and preventing childhood obesity ${ }^{(38)}$. However, an analysis of the Swedish IDEFICS cohort found that parental norms whether parents consumed sugar-sweetened beverages and whether they approved of their child's sugarsweetened beverages - were associated with increased odds of the child consuming at least one sugar-sweetened beverage per week, but exposure to commercial TV was significantly associated with sugar-sweetened beverage consumption even after controlling for social norms ${ }^{(39)}$. This suggests that addressing only parental reactions to pestering may not be enough to meaningfully improve children's diets and weight status.

The insight that parental guidance might not be effective enough has also driven proposals for stricter regulations on food advertising policy at both the European and country level. A global advocacy movement to limit marketing of unhealthy food products to children and adolescents is growing ${ }^{(40)}$. For example, Consumers International, a world federation of consumer groups across 120 countries, in conjunction with a broad range of like-minded allies, is campaigning for a 'Global Convention on Healthy Diets' to protect and promote healthy diets, using a similar political mechanism as the highly successful Framework Convention on Tobacco Control ${ }^{(41)}$. Such a convention could be a game changer. A 2013 WHO report on marketing of foods high in fat, salt and sugar to children shows that most of the countries within the WHO European region opt for self-regulatory approaches rather than hard government-led regulation ${ }^{(42)}$. To date, most of these food advertising policies in Europe are based on 
voluntary self-regulatory approaches by industry ${ }^{(43)}$. In a recent project report, we provide an overview of the different regulatory schemes regarding food advertising to children within the IDEFICS intervention countries of the present study ${ }^{(44)}$. Only Sweden, Estonia and Spain have a noteworthy national regulation in place to limit exposure of children to food marketing. But even here, governments rely largely on voluntary self-regulation of industry and such codes and pledges tend to be effective only if monitored closely by independent groups such as consumer organizations and if the reputational or financial consequences of non-compliance are substantial ${ }^{(45)}$. For instance, the 'EU Pledge' to prohibit advertising of products not fulfilling nutritional criteria to children under 12 years (2014) resulted in little impact ${ }^{(46)}$ and a recent examination of 281 products produced by EU Pledge signatory companies found that only twenty-nine of these products should have be marketed to children according to the WHO's criteria for a nutritionally balanced diet ${ }^{(47)}$.

\section{Conclusion}

In conclusion, many of the associations observed in the present study between pestering and diet and weight status were moderate in magnitude. Asking for items from TV had a fairly robust relationship with our outcomes of interest. In the prospective analyses, never asking for items from TV was a protective factor against incident obesity and overweight, while often asking was a risk factor for becoming overweight. Our findings, in conjunction with previous research, suggest the need for a closer examination of the role of advertising in children's health outcomes.

\section{Acknowledgements}

Acknowledgements: The authors are grateful for the support provided by school boards, headmasters and communities, and thank the IDEFICS children and their parents for participating in this extensive examination. Financial support: This work was done as part of the IDEFICS Project (www.idefics.eu), which is supported by the European Community within the Sixth RTD Framework Programme, Contract No. 016181 (FOOD). This study was funded by the European Community within the Sixth RTD Framework Programme Contract No. 016181 (FOOD). Conflict of interest: None. Authorship: Author contributions are as follows. C.Y.H.: design of analysis, statistical analysis and manuscript writing; L.L.: data collection, study design, manuscript writing and critical revisions of the manuscript; L.A.R.: study design, manuscript writing and critical revisions of the manuscript; all other authors: data collection and critical revisions of the manuscript. Ethics of human subject participation: The authors certify that all applicable institutional and governmental regulations concerning the ethical use of human volunteers were followed during this research and that the IDEFICS study passed the Ethics Review process of the Sixth Framework Programme (FP6) of the European Commission. Ethical approval was obtained from the relevant local or national ethics committees by each of the eight study centres: the Ethics Committee of the University Hospital Ghent (Belgium); the National Bioethics Committee of Cyprus (Cyprus); the Tallinn Medical Research Ethics Committee of the National Institutes for Health Development (Estonia); the Ethics Committee of the University of Bremen (Germany); the Scientific and Research Ethics Committee of the Medical Research Council, Budapest (Hungary); the Ethics Committee of the Health Office, Avellino (Italy); the Ethics Committee for Clinical Research Aragon (Spain); and the Regional Ethical Review Board of Gothenburg (Sweden). All parents of the participating children gave written informed consent to data collection, examinations, collection of samples, subsequent analysis and storage of personal data and collected samples. Additionally, each child gave verbal consent after being verbally informed in simple terms, due their young age, about the study by a study nurse. This consent process was not further documented, but it was subject to central and local training and quality control procedures. Study participants and their parents could consent to single components of the study, while abstaining from others. All procedures were approved by the above-mentioned ethics committees.

\section{References}

1. McGinnis JM, Gootman JA \& Kraak VI (2006) Food Marketing to Children and Youth: Threat or Opportunity? Washington, DC: National Academies Press.

2. McDougall J \& Chantrey D (2004) The making of tomorrow's consumer. Young Consum 5, 8-18.

3. Kraak VI \& Story M (2015) Influence of food companies brand mascots and entertainment companies' cartoon media characters on children's diet and health: a systematic review and research needs. Obes Rev 16, 107-126.

4. Harris JL, Schwartz MB \& Brownell KD (2010) Marketing foods to children and adolescents: licensed characters and other promotions on packaged foods in the supermarket. Public Health Nutr 13, 409-417.

5. Mehta K, Phillips C, Ward P et al. (2012) Marketing foods to children through product packaging: prolific, unhealthy and misleading. Public Health Nutr 15, 1763-1770.

6. Lythgoe A, Roberts C, Madden AM et al. (2013) Marketing foods to children: a comparison of nutrient content between children's and non-children's products. Public Health Nutr 16, 2221-2230.

7. Kelly B, Halford JC, Boyland EJ et al. (2010) Television food advertising to children: a global perspective. Am J Public Health 100, 1730-1736.

8. Boyland EJ, Harrold JA, Kirkham TC et al. (2011) The extent of food advertising to children on UK television in 2008. Int J Pediatr Obes 6, 455-461.

9. Romero-Fernandez MM, Royo-Bordonada MA \& RodriguezArtalejo F (2013) Evaluation of food and beverage television advertising during children's viewing time in Spain using the 
UK nutrient profile model. Public Health Nutr 16, 1314-1320.

10. Story M \& French S (2004) Food advertising and marketing directed at children and adolescents in the US. Int J Behav Nutr Phys Act 1, 3.

11. Rito A, Purnell L, Gwozdz W et al. (2015) Influence of Food Marketing and Media - on Internet, Social Networks and Other Channels. Report T7.3.2 delivered for I.Family Determinants of eating behavior in European children, adolescents and their parents, funded by the European Commission FP7, Project No. 266044. Copenhagen: Copenhagen Business School.

12. Cairns G, Angus K, Hastings G et al. (2013) Systematic reviews of the evidence on the nature, extent and effects of food marketing to children. A retrospective summary. Appetite 62, 209-215.

13. World Health Organization (2010) Set of Recommendations on the Marketing of Foods and Non-Alcoholic Beverages to Children. Geneva: WHO.

14. Dobbs R, Sawers C, Thompson F et al. (2014) Overcoming Obesity: An Initial Economic Analysis. London: McKinsey Global Institute.

15. McDermott L, O'Sullivan T, Stead M et al. (2006) International food advertising, pester power and its effects. Int J Advert 25, 513-539.

16. Spungin P (2004) Parent power, not pester power. Young Consum 5, 37-40.

17. Henry HK \& Borzekowski DL (2011) The nag factor: a mixed-methodology study in the US of young children's requests for advertised products. J Child Media 5, 298-317.

18. Galst JP \& White MA (1976) The unhealthy persuader: the reinforcing value of television and children's purchaseinfluencing attempts at the supermarket. Child Dev $\mathbf{4 7}$ 1089-1096.

19. Ebster C, Wagner U \& Neumueller D (2009) Children's influences on in-store purchases. J Retail Consum Serv 16, 145-154.

20. Morales E (2000) The nag factor: measuring children's influence - understand child-parent interaction to make sense of nagging and maximise child influence on purchases. ADMAP 3, 35-37.

21. Ogba I-E \& Johnson R (2010) How packaging affects the product preferences of children and the buyer behaviour of their parents in the food industry. Young Consum 11, 77-89.

22. Cornwell TB \& McAlister AR (2011) Alternative thinking about starting points of obesity. Development of child taste preferences. Appetite 56, 428-439.

23. Drewnowski A (1997) Taste preferences and food intake. Annu Rev Nutr 17, 237-253.

24. Ahrens W, Bammann K, Siani A et al. (2011) The IDEFICS cohort: design, characteristics and participation in the baseline survey. Int J Obes (Lond) 35, Suppl. 1, S3-S15.

25. De Henauw S, Verbestel V, Marild S et al. (2011) The IDEFICS community-oriented intervention programme: a new model for childhood obesity prevention in Europe? Int J Obes (Lond) 35, Suppl. 1, S16-S23.

26. De Henauw S, Huybrechts I, De Bourdeaudhuij I et al. (2015) Effects of a community-oriented obesity prevention programme on indicators of body fatness in preschool and primary school children. Main results from the IDEFICS study. Obes Rev 16, Suppl. 2, 16-29.

27. De Bourdeaudhuij I, Verbestel V, De Henauw S et al. (2015) Behavioural effects of a community-oriented setting-based intervention for prevention of childhood obesity in eight European countries. Main results from the IDEFICS study. Obes Rev 16, Suppl. 2, 30-40.

28. Marshall D, O'Donohoe S \& Kline S (2007) Families, food, and pester power: beyond the blame game? J Consum Behav 6, 164-181.
29. Carey L, Shaw D \& Shiu E (2008) The impact of ethical concerns on family consumer decision-making. Int $J$ Consum Stud 32, 553-560.

30. Powell S, Langlands S \& Dodd C (2011) Feeding children's desires? Child and parental perceptions of food promotion to the 'under 8s'. Young Consum 12, 96-109.

31. Ahrens W, Pigeot I, Pohlabeln H et al. (2014) Prevalence of overweight and obesity in European children below the age of 10. Int J Obes (Lond) 38, Suppl. 2, S99-S107.

32. Lanfer A, Hebestreit A, Ahrens W et al. (2011) Reproducibility of food consumption frequencies derived from the Children's Eating Habits Questionnaire used in the IDEFICS study. Int J Obes 35, Suppl. 1, S61-S68.

33. Bel-Serrat S, Mouratidou T, Pala V et al. (2014) Relative validity of the Children's Eating Habits Questionnaire-food frequency section among young European children: the IDEFICS Study. Public Health Nutr 17, 266-276.

34. Lissner L, Lanfer A, Gwozdz W et al. (2012) Television habits in relation to overweight, diet and taste preferences in European children: the IDEFICS study. Eur J Epidemiol 27, 705-715.

35. United Nations Educational, Scientific and Cultural Organization (1997) International Standard Classification of Education: ISCED 1997. http://www.unesco.org/education/ information/nfsunesco/doc/isced_1997.htm (accessed March 2015).

36. Swedish Ministry of Culture (2010) Radio and Television Act. SFS No. 2010:696. Stockholm: Ministry of Culture.

37. Chamberlain LJ, Wang Y \& Robinson TN (2006) Does children's screen time predict requests for advertised products? Cross-sectional and prospective analyses. Arch Pediatr Adolesc Med 160, 363-368.

38. World Obesity Federation (2014) Obesity Prevention in Children in Pre-School Years: Policies and Evidence. Brussels: World Obesity Federation.

39. Olafsdottir S, Berg C, Eiben G et al. (2014) Young children's screen activities, sweet drink consumption and anthropometry: results from a prospective European study. Eur J Clin Nutr 68, 223-228.

40. World Cancer Research Fund International (2015) Restrict Food Advertising and Other Forms of Commercial Promotion. London: WCRF International.

41. Consumer International \& World Obesity Federation (2014) Recommendations Towards a Global Convention to Protect and Promote Healthy Diets. London: Consumer International and World Obesity Federation.

42. World Health Organization (2013) Marketing of Foods High in Fat, Salt and Sugar to Children: Update 2012-2013. Copenhagen: WHO Regional Office for Europe.

43. Ronit K \& Jensen JD (2014) Obesity and industry selfregulation of food and beverage marketing: a literature review. Eur J Clin Nutr 68, 753-759.

44. Rito A, Gwozdz W \& Reisch L (2016) Overview of Regulatory Framework on Food Marketing Towards Children in the I.Family Countries. D 7.3.3. Report Prepared for I.Family Study. Copenhagen: Copenhagen Business School.

45. Shelton M (2011) Manual for Monitoring Food Marketing to Children. London: Consumers International.

46. Jensen JD \& Ronit K (2015) The EU pledge for responsible marketing of food and beverages to children: implementation in food companies. Eur J Clin Nutr 69, 896-901.

47. Huizinga O \& Kruse M (2016) Food industry selfregulation scheme 'EU Pledge' cannot prevent the marketing of unhealthy foods to children. Obes Med 1, 24-28. 